\title{
Condicionantes SOCIAIS E TRAJETÓRIAS SINGULARES: HABITUS COMO CHAVE ANALÍTICA EM PROCESSOS DE CONSTITUIÇÃO DE ELOS DE PERTENÇA E FRONTEIRAS SIMBÓLICAS
}

\author{
Ana Lúcia de CASTRO*
}

\begin{abstract}
RESUMO: O artigo é parte de uma pesquisa de campo realizada em um bairro da perferia de Santo André, Grande São Paulo, e discute os sentidos de pertença, ou não, à classe média, por parte dos moradores, frente às políticas de inclusão social implementadas na primeira década dos anos 2000, pelos governos estadual e federal. Em um segundo momento enfatiza as fronteiras simbólicas estabelecidas por um grupo de famílias recém transferidas de área de favela para um condomínio de prédios entregue como parte da política habitacional do estado de São Paulo, problematizando a preponderância das singularidades das trajetórias individuais que perpassam múltiplos espaços sociais na contemporaneidade - quando se opera com o conceito de habitus.
\end{abstract}

PALAVRAS-CHAVE: Fronteiras sombólicas. Elos de pertença. Agentes x estrutura. Condicionantes sociais. Habitus.

Introdução: Contexto etnográfico e considerações metodológicas

A reflexão proposta neste artigo parte de uma pesquisa etnográfica realizada no Jardim Santo André, um bairro da periferia do município de Santo André, Grande São Paulo, que teve como uma das preocupações centrais a discussão dos

UNESP - Universidade Estadual Paulista "Júlio de Mesquita Filho". Faculdade de Ciências e Letras. Campus de Araraquara. Araraquara - SP - Brasil.14800-901 - castroanalucia75@gmail.com. https://orcid.org/0000-0002-6165-7722. 
sentidos de pertença, ou não, à classe média, por parte dos moradores, frente às políticas de inclusão social implementadas na primeira década dos anos 2000, pelos governos estadual e federal. Este artigo busca analisar, especificamente, as fronteiras simbólicas estabelecidas por um grupo de famílias recém transferidas de área de favela para um condomínio de prédios, entregue como parte da política habitacional do governo do estado de São Paulo, problematizando a preponderância das singularidades das trajetórias individuais - que perpassam múltiplos espaços sociais na contemporaneidade - quando se opera com o conceito de habitus.

Nas visitas ao bairro, caminhávamos por suas ruas e vielas, abordando aleatoriamente algumas pessoas e sendo, muitas vezes, abordados. Nesta fase, de sondagem exploratória, muitos não demonstravam interesse em conversar, enquanto outros convidavam-nos a entrar e falavam avidamente sobre o que perguntávamos. Assim, muitas conversas foram realizadas sem agendamento prévio, na rua, num bar, na sala da residência, ou mesmo em pé, no portão. Após esta primeira fase de sondagens, pudemos ter a noção do quão heterogêneo é o local, tanto espacial como socialmente.

Figura 1: Vista panorâmica do Jardim Santo André, com a cidade de Santo André-SP ao fundo

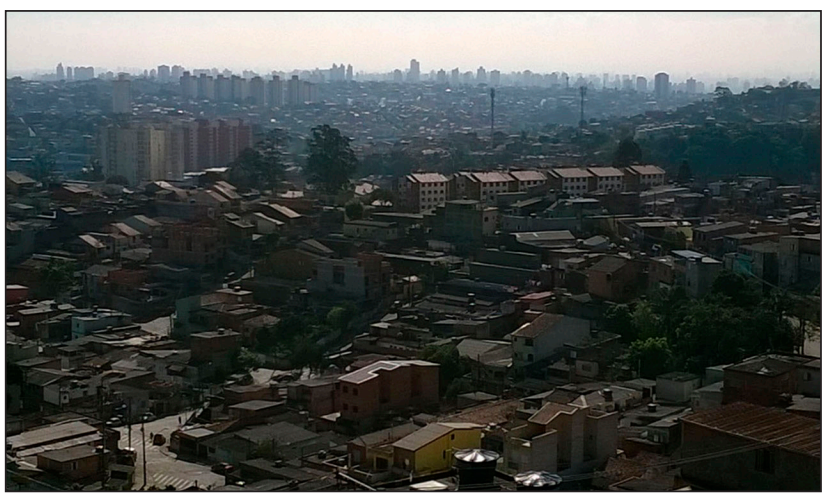

Fonte: Acervo pessoal da autora. 
Condicionantes sociais e trajetórias singulares: habitus como chave analitica em processos de constituição de elos de pertença e fronteiras simbólicas

Figura 2: Vista panorâmica do Jardim Santo André, com a barreira natural ao fundo

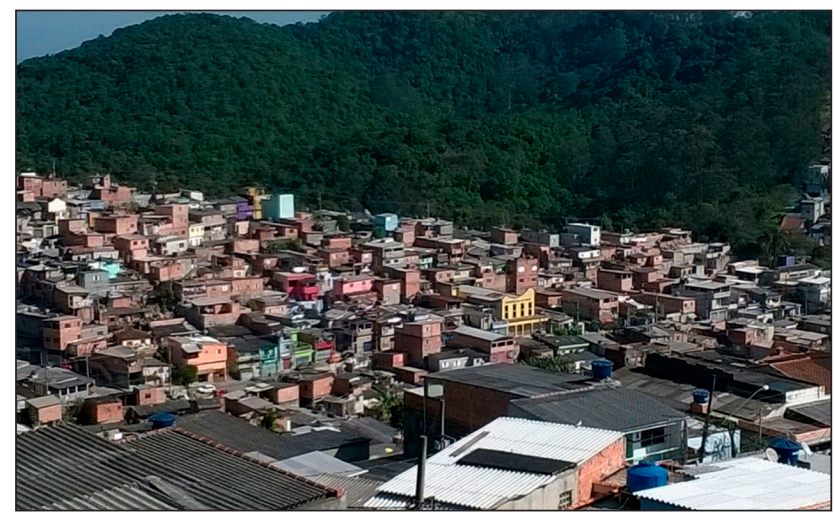

Fonte: Acervo pessoal da autora.

Em levantamento realizado pela Companhia de Desenvolvimento Habitacional e Urbano (CDHU) ${ }^{1}$. entre 2009 e 2010, identificou-se no bairro 5.799 famílias residentes em núcleos de favelas, caracterizados pela ocupação de propriedade alheia (pública ou particular) dispostas de forma desordenada e densa, carentes, em sua maioria, de serviços públicos essenciais; deste total, 980 família residem em áreas que passaram por processos de urbanização. O bairro conta, ainda, com famílias residentes em conjuntos de prédios (condomínios), construídos e financiados pela CDHU, em situação regular.

Figura 3: Área de risco recentemente desocupada pela CDHU (barranco desmatado pelos ocupantes retirados)

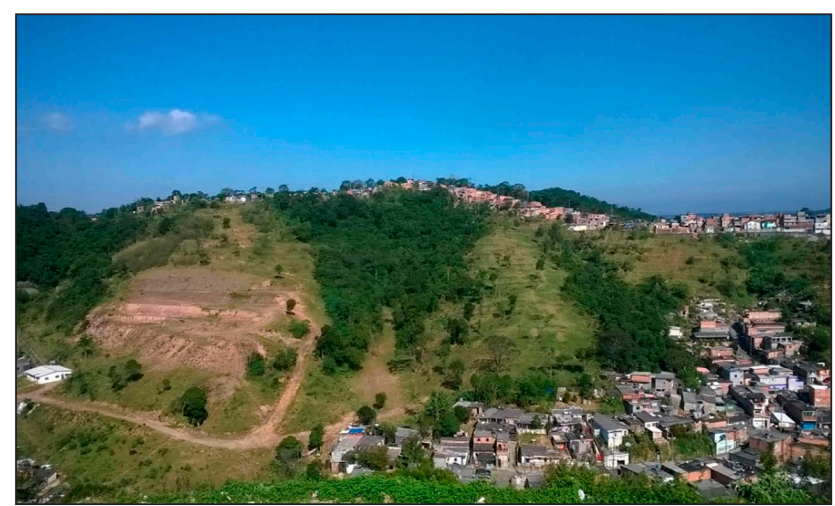

Fonte: Acervo pessoal da autora.

1 Companhia de Desenvolvimento Habitacional e Urbano, órgão ligado à Secretaria de Habitação do Estado de São Paulo. O bairro vem sendo alvo de intervenção de políticas habitacionais desde meados da década de 80 . 
Alguns trechos do bairro contam com infra-estrutura: asfalto, fornecimento de luz elétrica e água tratada, além de serem compostos por casas de alvenaria, algumas com três vagas de garagem, grades, jardim, pintura e acabamento externo. São, em geral, os pedaços do bairro formados há mais tempo, quando a CDHU atendeu as primeiras famílias que ocuparam o local, contemplando-os com casas térreas, conforme a política habitacional do momento. As primeiras famílias contempladas com as casinhas da $\mathrm{CDHU}$, em sua maioria, quitaram a dívida com a Cia, ampliaram e reformaram suas casas e muitas são comerciantes na região.

Saindo deste lado mais urbanizado do bairro, após descer um barranco, o que encontramos são casebres auto-construídos em alvenaria, sem nenhum tipo de acabamento, e barracos em madeirite. Em pontos mais isolados, sem acesso para veículos, os moradores caminham até $3 \mathrm{~km}$ para chegar ao ponto de ônibus mais próximo.

Figura 4: A viela mais afastada da avenida principal



Fonte: Acervo pessoal da autora.

Figura 5: Barracos de madeira e auto-construções em alvenaria. Área em espera do atendimento da CDHU

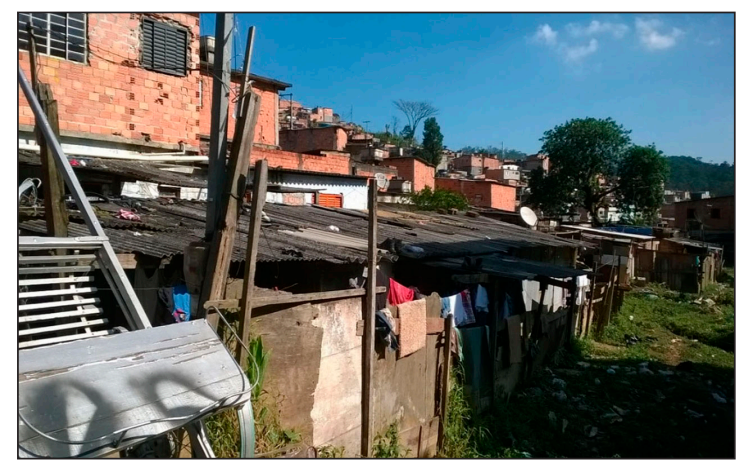

Fonte: Acervo pessoal da autora. 
Nesses locais encontramos famílias morando em situação irregular à espera de atendimento. Ao nos afastarmos mais das vias principais, adentramos em vielas nas quais se acumulam minúsculos barracos de madeirite e/ou alvenaria precária, de um ou dois cômodos. Um pouco mais adiante, ao final da subida de um grande morro, nos deparamos com escombros de demolição e vestígios de lares (colchões, portas de guarda-roupas, brinquedos, utensílios de cozinha) deixados para trás pelos moradores retirados do local.

Em nossas caminhadas pelo bairro, tanto em suas ruas asfaltadas, largas e planas, como nas tortuosas vielas, éramos observados com curiosidade e estranheza. Em algumas situações éramos abordados, quando, por exemplo, parávamos para nos localizarmos pelo mapa ou tomar água em algum dos vários pequenos bares existentes, respondíamos à perguntas como: Vocês são daqui? O que vocês estão fazendo mesmo? Também abordávamos pessoas em calçadas e batíamos em portas para solicitar um tempo de conversa. Algumas dessas conversas eram aprofundadas em entrevistas, marcadas previamente.

Figura 6: Moradores subindo a escadaria em uma das vielas onde não há acesso para carro

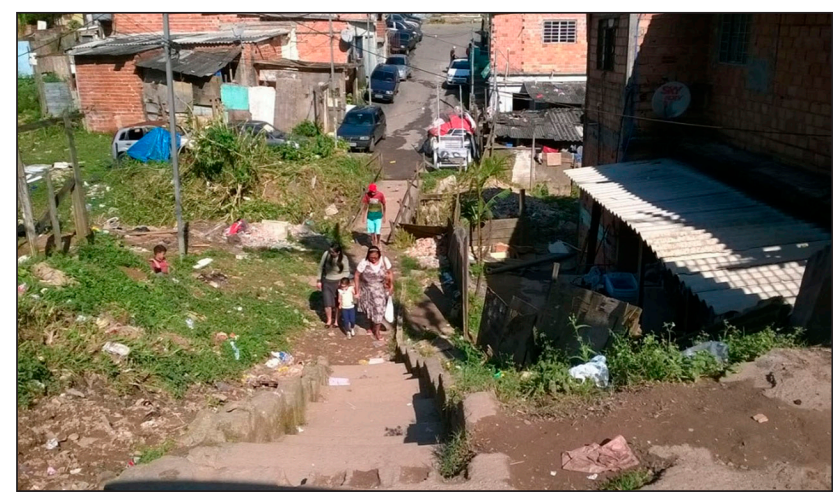

Fonte: Acervo pessoal da autora.

Estas primeiras abordagens nos permitiram organizar a próxima etapa do trabalho de campo e preparar o roteiro de questões para as entrevistas, bem como definir o perfil das pessoas a serem entrevistadas. A partir das entrevistas, construímos os critérios para a realização dos grupos focais, detalhados mais adiante. 
Figura 7: Esgoto a céu aberto

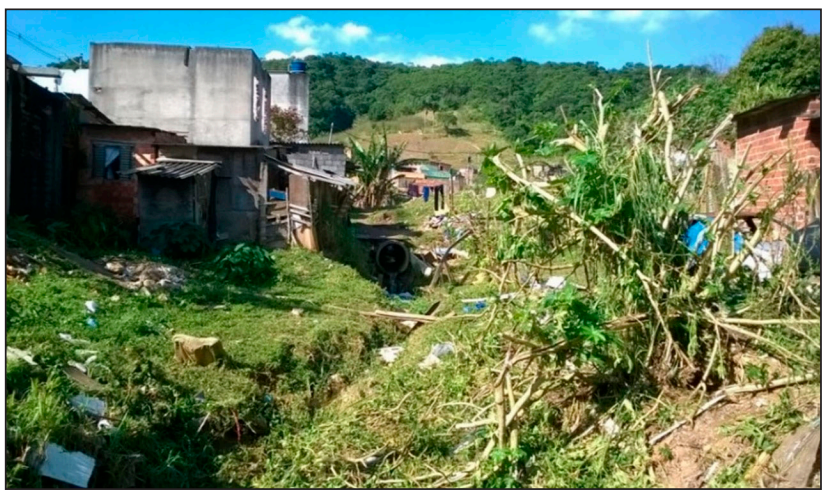

Fonte: Acervo pessoal da autora.

\section{Pertencimento de classe}

Uma das perguntas colocadas por esta pequisa referia-se ao sentido de pertencimento, ou não, às chamadas classes médias, na perspectiva dos interlocutores, moradores do bairro. Cabe lembrar que no contexto em que realizávamos o trabalho de campo (ano de 2015), já havia sido difundido o discurso governamental de que o Brasil havia se tornado um país de classe média, com a realização da inclusão social, via políticas públicas, bem como com o incremento da renda dos mais pobres e o consequente acesso ao consumo de bens nunca antes experimentado.

Embora totalmente frágil do ponto de vista sociológico, a classificação proposta pelos técnicos do governo federal indicava algo novo. Entre 2004 e 2010, 32 milhões de pessoas ascenderam socialmente, ainda que discordemos da denominação, teriam ascendido à categoria de classes médias, segundo estudo da Secretaria de Assuntos Estratégicos (SAE) da Presidência da República. Por este estudo, estimava-se que o Brasil tinha 104 milhões de pessoas na classe média, o que representava $53 \%$ da população brasileira - 20\% estariam na classe alta e $28 \%$ na baixa, enquanto, sob o mesmo critério de classificação, apenas $38 \%$ da população estaria na classe média em $2002 .^{2}$

Em um das várias caminhadas que realizamos pelo bairro, avistamos uma longa fila e logo descobrimos tratar-se de distribuição de uma cesta básica, composta por arroz, feijão, óleo e um cacho de bananas. O local da distribuição é a Associação

2 Conforme estudo divulgado em setembro de 2012 pela Secretaria de Assuntos Estratégicos da Presidência da República. Disponível em: <https://issuu.com/sae.pr/docs/cartilha-vozes-classe-media_ vers_o_9140f5eabbda7a/27.>. Acessado em: 05 fev. 2019. 
de moradores e a pessoa que organiza é Célia ${ }^{3}$, que depois se demonstrou liderança e figura histórica no local, proprietária da casa ao lado do galpão que abriga a Associação. Inicio uma conversa com ela que pede para marcar para um outro dia, pois está naquele momento muito ocupada no atendimento às pessoas. Numa segunda visita, realizamos uma longa conversa, na qual ela contou que mudou para o bairro há 27 anos, quando integrava um grupo que realizou as primeiras ocupações no local. Seu discurso mais articulado, em relação aos demais interlocutores aos quais esta pesquisa deu voz, e seu papel de liderança vão se evidenciando no decorrer da conversa.

Célia expressa a percepção de uma grande melhora recente, tanto das condições de vida, como das oportunidades que se colocam para os moradores do bairro. Quando solicitada a falar mais um pouco sobre as mudanças que percebia na vida das pessoas do local, ela aponta como marcadores a chegada dos técnicos sociais da CDHU e as políticas inclusivas implantadas pelo governo federal:

Nossa! Mudou a visão, a atitude...um processo muito bom que eles passaram. A urbanização... hoje já não falam mais comunidade, falam bairro. Tem direito à escola, a estudar, a fazer faculdade. E também a troca né: se tenho direito também tenho deveres. Eles começaram a ter essa visão que não tinham [...]. O governo federal ajuda bastante também, com a bolsa família, essas coisas $[\ldots]{ }^{4}$

Quando questionada se poderíamos dizer que as pessoas do bairro agora eram de classe média, percebemos que a visão economicista difundida pelo governo federal - que define o pertencimento à classe media a partir da renda per capita penetrou no discurso de nossa interlocutora:

Agora essas pessoa tudo pode dizer que são da classe média..... O poder aquisitivo delas tão melhor e a questão da moradia....temos um grupo mínimo que vive numa moradia indigna, sub humano.... mas a maioria já se sente da classe média...com certeza. Posso te garantir. Temos pessoas fazendo faculdade... já é uma coisa de outro mundo. Cursos... eles se sentem sim. Pelo jeito, modo de falar. Às vezes eu até brinco:

— Ei! Tá pagando, né? Poder aquisitivo grande. ${ }^{5}$

\footnotetext{
3 Todos os interlocutores referidos neste texto receberam nomes fictícios, a fim de preservar o anonimato.

4 Depoimento de Célia, oitava série, 49 anos, presidente da Associação de moradores, concedido a esta pesquisa em junho de 2014.

5 Idem.
} 
Tentando explorar um pouco mais a sua visão sobre a classe média, insisti na pergunta sobre o que diferencia a classe média dos pobres, e a interlocutora aponta a ideia de oportunidade:

[...] acho assim: é o poder aquisitivo que temos, uma boa moradia.... eu não digo que é pobre, é que não teve uma oportunidade...não ter tido oportunidade de ter uma moradia de ter um curso profissionalizante, de ter estudo, isso faz com que eles tenham uma precariedade tremenda, sabe, e não tem como... como eu sobrevivo a esse mundo... a esse país, se eu não tenho apoio do poder público?

Curioso notar que, nesse ponto da conversa, Célia assume o pertencimento à classe média, falando em primeria pessoa, como alguém que compartilha dos requisitos para o pertencimento: poder aquisistivo e oportunidades. Contudo, a conversa com Célia indicou que o sentido de pertença à classe média carrega certa ambiguidade, sendo positivado e desejado, quando o que está em pauta é o pertencimento pela inclusão via políticas públicas, mas negativado, quando se trata da apropriação de bens para imitação, visando passar por, ser identificado como classe média. Como exemplo, podemos citar os chistes e as referências irônicas ao modo de se vestir; percebidos nos bazares beneficentes organizados pela Associação de moradores, nos quais as roupas de grife doadas à comunidade são desfiladas numa passarela improvisada, quando se ridicularizam ironicamente não só as modelos e atrizes, mas as patroas ou qualquer pessoa referida ao universo dos de cima, sempre retratados como esnobes e pessoas que não sabem viver a vida. Os diversos sentidos atribuídos à idéia de pertencimento ou não à classe média foram se evidenciando em diferentes situações de campo, indicando que no local, as fronteiras simbólicas, sempre móveis e relacionais, passavam, naquele momento, por um intenso processo de redefinição.

\section{Trajetórias,singularidades e fronteiras simbólicas}

Em certo momento da pesquisa, os técnicos do escritório local da $\mathrm{CDHU}^{7}$ comentavam com entusiasmo a entrega de um empreendimento inovador na história do local. Seria uma grande novidade, pois este condomínio de prédios contaria com área de lazer, salão de festas e portaria com guarita, diferenciando-se dos anteriores empreendimentos entregues pela Cia.

\footnotetext{
6 Idem.

7 Contávamos com a infraestrutura do escritório local da CDHU, no qual trabalham em média 4 técnicos atendendo à população cadastrada e à espera de atendimento. Sempre simpáticos, nos permitiam utilizar o banheiro, tomar água e café, além de fornecerem informações sobre o local e os moradores.
} 
Para este conjunto de apartamentos foram enviadas 230 famílias, oriundas da favela Missionários, onde havia barracos precários à beira de um córrego que cumpria o papel de esgoto a céu aberto, com ocorrência de enchentes constantes. Ao serem retiradas da favela, estas famílias foram transferidas para um alojamento que seria provisório, mas onde acabaram ficando por cinco anos, em condições bastante insalubres.

Solicitamos aos técnicos da CDHU, então, o cadastro dos moradores agora residentes neste novo empreendimento, fizemos contato telefônico e marcamos entrevistas para abordagens individuais. Com o desenrolar das entrevistas, foi se evidenciando a existência de dois grupos de moradores que se relacionavam de maneira diferenciada, tanto com a nova condição de moradia, como com o universo de consumo de maneira geral. De um lado, aqueles que se viam satisfeitos com a mudança e rapidamente se adaptaram, organizando-se para pagar as contas mensais que antes não faziam parte de suas despesas, como o condomínio e a parcela do financiamento do apartamento. Estes organizavam as finanças, planejavam as compras, relacionavam-se com o universo dos bens de consumo mais frequente e planejadamente. Percebem claramente a mudança em sua condição social, expressam melhora na auto-estima e desenvolvem um pensamento prospectivo, vislumbrando um futuro melhor para os filhos que, no mínimo, herdarão o imóvel que estavam pagando.

De outro lado, temos o grupo dos insatisfeitos que percebiam dificuldades em se adaptar. Não conseguiam se organizar para pagar as despesas mensais relativas ao apartamento, compravam sem planejamento, não tinham garantia de que poderiam repor os alimentos após o consumo, conviviam com a incerteza, dependendo de doações ou rendimentos advindos de bicos e rendas esporádicas para a subsistência; estes moradores não estavam certos da melhora nas condições de vida, apontando o passado recente no alojamento, barraco ou casa na área de favela, como mais adequado às suas necessidades. Tomamos este divisor de águas como critério para a montagem de dois grupos focais.

Curiosamente, fomos percebendo que a passagem da vida na favela para a vida em condomínio não ocorre de maneira homogênea, ou seja, embora as famílias envolvidas tenham uma mesma origem social e, em tese, compartilhem um mesmo habitus (Bourdieu, 2007) revelam uma adaptação maior ou menor aos incômodos e benefícios próprios ao novo modo de habitar.

O conceito de habitus, central na reflexão bourdiana, foi formulado em busca da superação da dicotomia entre objetividade e subjetividade, preocupação central na construção de seu arcabouço teórico, como aponta o próprio autor (BOURDIEU, 1987) e comentadores de sua obra (ORTIZ,1983; PETERS, 2013). Em sua formulação, Bourdieu considera o filtro subjetivo do agente, ao apontá-lo como estruturante, sem, contudo, desconsiderar a objetividade da estrutura social que o formata: 
[...] o habitus constitui-se em estrutura estruturante que organiza as práticas e a percepção das práticas, o habitus é também estrutura estruturada; o princípio da divisão das classes lógicas que organiza a percepção do mundo social, é por sua vez o produto da incorporação da divisão em classes sociais (BOURDIEU, 2007, p.164).

Como indicou Renato Ortiz (1983), a praxiologia proposta por Bourdieu busca superar os pontos cegos de um debate epistemológico que coloca em campos antagônicos o objetivismo e a fenomenologia. O primeiro, representado nas ciências sociais pelo pensamento durkheimiano, acentua a transcendência do social, reificadamente entendido como coisa, dotada de exterioridade e capacidade coercitiva. Para a segunda vertente, representada nas ciências sociais por Weber, o ponto de partida da análise é a experiência individual e a objetividade só pode ser apreendida através das ações individuais. O mundo objetivo é produto de uma rede intersubjetiva que só ganha algum significado através de interações, ou seja, "resultado de ações dirigidas para o outro e que adquirem significado na medida em que o "outro" compartilha comigo o mesmo mundo social no qual tais ações se desenrolam". (ORTIZ, 1983, p.12).

A praxiologia bourdiana, contudo, não se limita a rejeitar o conhecimento objetivista, mas busca incorporá-lo, considerando a estruturação social das relações intersubjetivas. Neste sentido, ao lançar luz sobre o agente, não reproduz simplesmente os argumentos da abordagem fenomenológica, mas os supera, ao introduzir a questão do poder, apontando que a interação se desenrola de forma estruturada, em espaços sociais específicos, permeados por relações de poder. Em sua sociologia da práxis, portanto, Bourdieu (1983) busca capturar a relação históricodialética entre as trajetórias individuais dos agentes e a reprodução/produção das estruturas sociais, ou, em outras palavras, busca encontrar a mediação entre agente e estrutura social.

Embora a formulação dos conceitos de habitus e de campo tenham resultado deste esforço teórico em conciliar agente e estrutura ou subjetividade e objetividade, Bourdieu acaba, como aponta Peters (2013, p.56), por postular uma precedência "metodológica e ontológica do nível objetivo sobre o nível subjetivo", uma vez que o autor deixa pouca margem para considerarmos a possibilidade de os próprios agentes atuarem reflexivamente sobre as disposições inscritas em seus habitus e as transformarem. Esta possibilidade seria levada em conta, na reflexão de Bourdieu (1983), apenas em situações nas quais as disposições do habitus fossem ativadas em contextos diferentes dos que o produziram, ou seja, em circunstâncias que promoveriam uma quebra entre as condições de produção e as condições de exteriorização do habitus. Esta situação, denominada de hysteresis, pressupõe que o insight reflexivo do agente, levando-o a acessar pela primeira vez dimensões de seu próprio habitus, só seria possível em momentos de crise objetiva. 
Desse modo, Bourdieu (1983) pressupõe a necessidade de uma quebra sóciohistórica da relação ontológica entre subjetividades e estruturas objetivas para que o agente desempenhe uma prática inovadora e pautada pela reflexividade, e essa quebra - ou desajuste entre habitus e campo - ocorreria em raras situações de crise ou convulsão social. O ponto crítico é que, contemporaneamente, esta situação de desajuste não é assim tão rara, pois os agentes são compelidos, cotidianamente, a atuar em uma ampla gama de espaços sociais, aos quais as disposições carregadas por seus habitus não estão ajustadas.

Neste sentido, podemos trabalhar a ideia de que as diferentes adaptações das famílias à vida em condomínio estão ligadas à origem e ao percurso por elas transcorrido, que pode, entre outras coisas, envolver encontros e desencontros com empregadores e órgãos públicos, que teriam, de certo modo, desempenhado papel educativo, propiciando a aquisição de capital social (BOURDIEU, 2007) e fornecendo ou não a chave de acesso a esse universo, estranho ao seu originário. No caso do grupo dos não adaptados $^{8}$, ocorre uma certa transposição dos modos de ocupação do espaço - tal qual os operados na favela - para o condomínio (cachorros soltos, varais no primeiro andar, pequenos comércios com produtos expostos nas janelas, lixo sendo atirado pela janela, audição de música em alto volume), contrariando a expectativa do outro grupo, que embora também seja constituído por oriundos da favela, é composto por famílias que contam com fonte de renda fixa e, de alguma maneira, incorporaram as regras de etiqueta e convivência que envolvem a vida em condomínio (ordem, limpeza, discrição).

Um dos principais aspectos diferenciadores dos dois grupos reside na percepção ou não de melhora nas condições de vida após a mudança para o apartamento. Para o grupo composto pelos adaptados, a mudança implicou em melhora material, pois, dentre outras coisas, as frequentes enchentes não destróem mais a mobília e o novo endereço, fora da favela, facilitou a conquista de emprego. Exemplo desta percepção encontra-se no depoimento abaixo:

[...] eu agradeço todos os dias a Deus a oportunidade de ter vindo pra cá, apesar de todos os problema que tem, todas as reclamações. O meu apartamento, graças a Deus, não tem nenhum tipo de problema. Eu brigo por causa do problema dos outros, e muito, porque eu não acho justo, e minha vida no meio de tudo isso mudou pra melhor, graças a Deus. ${ }^{9}$

\footnotetext{
8 As expressões adaptados e não adaptados derivaram da referência recorrente, pelo grupo de moradores satisfeitos, a si próprios e aos outros, respectivamente, com frases como: "Eles não se adaptam" ou "A gente tem que se adaptar à vida em condomínio".

9 Depoimento de Zuleide, sexta série, 42 anos, diarista desde os 14, concedido para esta pesquisa em outubro de 2015 .
} 
Outro entrevistado destaca, em sua percepção de melhoria de condições de vida, a fartura de alimentos: "Em comparação a lá, a gente tá no céu. Tem um monte de coisa na geladeira, então é uma boa coisa pra viver, né." 10

Para Ana Paula, a melhoria nas condições de moradia e de vida é percebida em várias dimensões: espaço e número de cômodos, aparência do lugar, a infraestrutura com área de lazer, entrega de correio e ponto de ônibus próximo.

Melhorou 100\%. Acho assim: o espaço para os meus filhos, porque lá morava num cômodo e um banheiro. Cada um tem seu quarto...ter onde andar. La não tinha onde andar, saía de um canto tava no mesmo lugar. Aqui não. Aqui ele tem espaço pra brincar no parquinho. A menina fica a vontade.... quando eu ia fazer alguma coisa eu não podia dar o endereço de lá porque nunca chegava eu tinha que ir no correio. Aqui não, a gente pega na portaria, a gente não precisa se preocupar de ir atrás da conta. Porque lá eles não entravam pra entregar. As vezes dava o endereço do vizinho e ia buscar no vizinho... Lá tinha que andar bastante até o ponto de ônibus, quando chovia melava o pé de lama..... ${ }^{11}$

Além de ter um endereço fixo, esta mesma interlocutora refere o pagamento das contas relativas à prestação do apartamento e à manutenção do condomínio como um marcador da melhora da auto-estima, definida pela expressão ter postura: “(...) agora eu tenho postura, eu tenho contas para pagar no fim do mês, eu abro e fecho o portão para ir ao trabalho..."

Em contraposição, como representante do grupo daqueles julgam estar em piores condições na nova moradia, os aqui denominados inadaptados - destacamos o depoimento de Dona Luzia, que tinha como principal fonte de renda um pequeno negócio estabelecido em seu barraco, onde comercializava gêneros alimentícios, materiais de limpeza básicos, balas, doces e bebidas. Com a mudança para o condomínio está sendo impedida de manter esta fonte de renda e afirma preferir retornar ao alojamento, mesmo com a constante companhia dos ratos.

Eu vou pra qualquer lugar, mas isso aqui não é vida. Desde que eu possa trabaiá. Eu não escolho o lugar. Só que aqui tá assim, eu não posso trocá nem vendê, tem que esperar dois anos. Não foi bom vir pra cá, eu preferia fica no alojamento! Eu fiquei cinco anos e pouco lá. Olha, tirando a convivência dos ratos, mas os meus gatos comiam os ratos lá. E eu não tinha problema lá, eu vendia doce, cerveja, refrigerante, vendia tudo lá... E aqui, de onde vou tirar dinheiro? ${ }^{12}$

\footnotetext{
${ }_{10}$ Depoimento de Sr. Adalberto, quarta série, aposentado por invalidez, 61 anos, concedido para esta pesquisa em julho de 2015.

${ }_{11}$ Depoimento de Ana Paula, diarista, 34 anos, cursando ensino médio, concedido para esta pesquisa em julho de 2015.

12 Depoimento de D. Luzia, sem instrução formal, dona de pequeno comércio, 58 anos, concedido para esta pesquisa em agosto de 2015.
} 


\section{Condicionantes sociais e trajetórias singulares: habitus como chave analitica}

em processos de constituição de elos de pertença e fronteiras simbólicas

O mesmo tipo de percepção encontramos em Dona Edicleide, que tem dificuldades de pagar as contas e lida com o problema da drogadição de um dos filhos. Neste ponto do diálogo, seu discurso é cifrado, pois não pode falar abertamente no assunto, devido à presença do filho, com quem se preocupa por conta do envolvimento com drogas. Ela se queixa da proximidade e facilidade em obtenção, estando agora o tráfico em um ambiente mais confinado e, de certo modo, mais protegido de intervenções policiais.

Pra ser sincera eu estaria lá...eu tinha um pouquinho mais de paz. Era barraco, mas não ....parece que eu tinha mais sossego. Não tava essa confusão toda. Não sei, é que piorou depois que ele (o filho) veio pra cá, eu não sei. Antes, a gente não tinha que se preocupar em pagar nada, só com o que comer, agora é muita conta pra pagar. ${ }^{13}$

Foi evidenciando-se, portanto, que essas famílias, que antes se reconheciam como parte de um mesmo universo e se percebiam como pertencentes a uma mesma comunidade, agora assumem diferentes modos de lidar com a nova condição de moradia. Assim, assumir-se ou não em outra condição, como situados ou não em outra posição social, converte-se em uma importante fronteira simbólica estabelecida entre os dois grupos, a qual foi constantemente referida e reforçada durante as entrevistas com os moradores pertencentes ao grupo dos adaptados, que se referiam aos inadaptados como favelados, desordeiros, bagunceiros. Este julgamento negativo daqueles definidos como favelados configura-se numa situação, dentre as várias identificadas durante o trabalho de campo, que permite analogias com a relação entre os grupos de estabelecidos e outsiders analisados por Elias \& Scotson (2000), em seu clássico estudo sobre um povoado industrial localizado numa pequena cidade inglesa. Curioso notar como os moradores que foram contemplados pela política da CDHU - e se mostram satisfeitos, manifestando uma mudança de auto-imagem - e esforçam-se em criar e reforçar uma fronteira simbólica entre um NÓS e um ELES, esses últimos chamados de favelados, classificados como sem educação, porcos, ou por comentários como: "educação vem do berço". Similarmente, no clássico estudo referido, os estabelecidos moradores da parte mais antiga do bairro também classificavam os moradores mais recentes como desorganizados, sujos, por eles chamados de ratos, criando e cultuando uma hierarquia de status que acaba por levar os outsiders a introjetarem a idéia de que eram, de fato, seres humanos inferiores.

Um dos aspectos que mais provoca indignação aos adaptados refere-se, justamente, à ausência de hábitos de higiene e limpeza, revelada quando seus vizinhos atiram pela janela embalagens vazias e bitucas de cigarro, ou descartam

${ }^{13}$ Depoimento de D. Edicleide, segunda série, vendedora ambulante desempregada, 42 anos, concedido a esta pesquisa em agosto de 2015. 
papéis de bala e chicletes mascados pelas escadas dos prédios. Outra fonte de indignação refere-se ao não pagamento das contas relativas ao condomínio e à prestação do apartamento, como ilustram os depoimentos destacados a seguir:

[...] também tem aquelas pessoas que saiu de lá que já não pagava nada, chegou aí e não continua a pagar nada. Tá há um ano aí e nunca pagou nada, então eles pensa que aqui é favela. ${ }^{14}$

Eu tenho assim, uma coisa enlouquecida na minha mente: como que você tem a chance de ter a tua moradia, de ter um imóvel que você vai envelhecer, que você vai ficar ali, né, como é que você não paga? Que você assinou, né, que você fez um contrato com um banco, como que você não paga? Quer dizer, você pensa o quê? ${ }^{15}$

Em várias situações de entrevista com moradores adaptados, notamos a clara separação entre eles e aqueles que seriam os favelados, por eles definidos como portadores de uma condição essencial, naturalizando-a, como se não fosse possível dela sair jamais:

[...] ó ... você mora na favela, mas você não é a favela. Uma coisa é você morar no local por sua necessidade, outra coisa é você ser aquilo. É uma diferença gigantesca.... ${ }^{16}$

Então eles se comporta como favelado aí memo. Porque tem o que mora na favela, né, e tem o favelado. Eu me considero que eu morava na favela, mas eu não era favelado. Aí, nêgo passa pra cá e tem nêgo que nunca trabaiou na vida, nunca pagou nada, e eles (referindo-se à CDHU) pensa que é igual, e não é. ${ }^{17}$

Notamos que, embora estejam em condições de igualdade para recomeçar a vida, ou seja, usufruírem de uma mesma política pública - morando em apartamentos com divisão adequada de cômodos e acabamento íntegro, com infraestrutura de água e luz, asfalto e transporte público - algumas famílias percebem esta condição como uma oportunidade de mudar de patamar em sua luta para conquista de uma suposta melhoria de posição social, enquanto outras não detém alguns recursos - que podemos entender como capital cultural e social (BOURDIEU, 2007) - necessários para transpor o olhar para além das dificuldades encontradas no presente. Esta

\footnotetext{
${ }_{14}$ Depoimento de Sr. Adalberto, quarta série, aposentado por invalidez, 61 anos, concedido para esta pesquisa em julho de 2015.

15 Depoimento de Janeide, cursando ensino médio, diarista, 35 anos, concedido para esta pesquisa em outubro de 2015 .

16 Idem.

17 Depoimento de Sr. Adalberto, quarta série, aposentado por invalidez, 61 anos, concedido para esta pesquisa em julho de 2015.
} 
diferença tão marcante nas formas de apropriação dos recursos disponibilizados pela política habitacional, bem como na elaboração de projetos futuros, é um dos mais significativos divisores de água no grupo de famílias enfocado neste estudo, demarcando uma importante fronteira simbólica interna ao mesmo.

De fato, embora todas as famílias moradoras deste condomínio tenham sido deslocadas da mesma favela e habitado o mesmo alojamento por cinco anos, assim como todas relatem uma origem familiar muito similar - famílias vindas de zona rural, pais com baixa ou nenhuma escolaridade e que não contam com emprego fixo, exercendo ocupações temporárias - identificamos uma diferença marcante entre dois grupos de moradores, no que toca à sua auto-estima, à percepção de melhora das condições de vida e à elaboração de pensamento prospectivo. Esta diferença nos remete a uma ponderação teórica acerca da preponderância das condicionantes objetivas presentes na formulação bourdiana relativa à noção de habitus, bem como nos coloca a necessidade de buscar uma perspectiva analítica que enfatize a dimensão subjetiva das práticas, sem desconsiderar as condicionantes estruturais que formatam as disposições culturais.

Nesse sentido, nos aproximamos das reflexões de Lahire (2007), que aponta para a importância, na contemporaneidade, da heterogeneidade das instâncias socializadoras e pluralidade de espaços sociais por onde os agentes circulam. Em suas palavras:

[...] a realidade social é mais complexa do que a teoria da legitimidade cultural dá a entender. É o estudo sistemático das variações intra-individuais dos comportamentos culturais que obriga a que se vejam os deslocamentos efetuados por um mesmo indivíduo de um registro cultural para outro. (LAHIRE, 2007, p.800).

Para Lahire (2007), portanto, a pluralidade de disposições culturais, muitas vezes incoerentes, dificultaria a aplicação do conceito de habitus, em princípio pautado na unidade. Setton $(2002,2015)$ diverge desta perspectiva, contribuindo para o debate acerca da atualidade do conceito de habitus, ao apontar sua condição processual e mutável.

Contudo, ao contrário e diferente deste autor (referindo-se a Lahire), considera-se que o conceito de habitus continua sendo um instrumento de análise relevante para se compreender os processos socializadores atuais(...) Habitus é mediação que se constrói processualmente, em muitos momentos da trajetória dos sujeitos; um conjunto de experiências acumuladas e interiorizadas, passíveis de se modificarem e de se realizarem como respostas aos momentos de necessidade.(SETTON, 2015, p.1409). 
Reitero a necessidade de considerar o habitus um sistema flexível de disposição, não apenas resultado da sedimentação de uma vivência nas instituições sociais tradicionais, mas um sistema em construção, em constante mutação e, portanto, adaptável aos estímulos do mundo moderno: um habitus como trajetória, mediação do passado e do presente; habitus como história sendo feita; habitus como expressão de uma identidade social em construção. (SETTON, 2002, p.67, grifos meus).

A autora enfatiza que a circulação de referências identitárias e repertórios culturais - como parte do fluxo global de pessoas, signos e referências, característico da experiência social contemporânea - e a consequente pluralização de espaços sociais propiciariam ao indivíduo um processo de socialização mais híbrido, pois constituído por instituições e instâncias diversas.

A coexistência de distintas instâncias de socialização, com projetos múltiplos e uma maior circularidade de valores e referências identitárias, configura um campo da socialização híbrido e diversificado. Com base na discussão anterior, é possível ver essa nova configuração contribuindo para a construção de um habitus, a construção de um novo sujeito social, agora não apenas influenciado e determinado pelas instâncias tradicionais da socialização - a família e a escola. (SETTON, 2002, p.67).

É possível sugerir que o habitus construído por disposições híbridas (Setton, 2002) na contemporaneidade, possa infletir na teoria da distinção, quando observamos que, entre nossos interlocutores, o desejo de aquisição de bens de marca - cuja ocorrência é, predominantemente, entre os jovens - carrega a intenção de experimentar, mas não de imitar para tornar-se de outra classe social. Esta perspectiva analítica não desconsidera a desigualdade social e cultural que hierarquiza brutalmente nossas sociedades, como demonstra Bourdieu (2007), mas enfatiza a preocupação com a circulação de referências culturais diversas.

Assim sendo, em consonância com Setton (2002; 2015), nos afastamos de Lahire (2007) no que se refere às suas críticas à inviabilidade do habitus como conceito para compreensão da cultura contemporânea, mas concordamos com sua indicação de que se faz necessário ajustar o foco da análise bourdiana, enfatizando mais a dimensão subjetiva, relativa às singularidades das trajetórias individuais dos agentes.

Neste sentido, vale ressatar a relação com o universo do tráfico e o uso de drogas como um importante sinalizador das trajetórias individuais, marcadas pela pluralidade de pertencimentos sociais e simbólicos e pelos múltiplos espaços nos quais os indivíduos desenvolvem suas práticas culturais. A disponibilidade da droga 
e o convívio diário com os usuários e traficantes são colocados para todas as famílias do condomínio, mas o envolvimento dos filhos com esse universo - que em geral é devastador para a família, acabando em homicídios, roubos e desagregação - parece depender das trajetórias individuais. Pudemos testemunhar, em uma mesma família, o envolvimento de um adolescente com o tráfico, que resultou em seu assassinato, enquanto seu irmão um ano mais novo se manteve distante deste universo.

Em suma, há, evidentemente, condicionantes sociais, mas que, se tomados isoladamente, não sustentam suficientemente uma compreensão satisfatória. Contudo, convém ressaltar que a proposição de uma perspectiva que procure enfatizar a dimensão subjetiva na busca da compreensão das práticas e representações dos agentes, não implica na pressuposição de indivíduos autônomos, desprendidos das instituições sociais, mas remete ao conjunto das estruturas sociais que as definem.

Por fim, vale ressaltar que esta pesquisa vem somar-se aos esforços de aprofundar a reflexão sobre o pensamento de Pierre Bourdieu, ao iluminar a dimensão subjetiva na configuração das relações sociais e na trajetória dos agentes. Trata-se de uma postura teórica situada contra e com Bourdieu - na medida em que busca alargar a compreensão de questões por ele propostas - lançando luz para o polo das subjetividades na configuração da realidade social, mas partindo do reconhecimento de que sem suas originais e instigantes contribuições, a proposição desta pesquisa nem teria sido possível.

\section{SOCIAL CONDITIONERS AND SINGULAR TRAJECTORIES: HABITUS AS ANALYTICAL KEY IN PROCESSES FOR THE CONSTITUTION OF TIES OF BELONGING AND SYMBOLIC BOUNDARIES}

ABSTRACT: This article is based on a field research conducted in a neighborhood in the periphery of Santo André, in the state of São Paulo, Brazil and discusses the sense of belonging to the middle class by its residents, in the face of social inclusion policies implemented in the first decade of the twenty-first century by the state and federal governments. This work also emphasizes the symbolic boundaries established by a group of recently transferred households from a slum area to a condominium of buildings, delivered as part of the housing policy of the State of São Paulo, problematizing the predominance of singularities of the individual trajectories, which pass through multiple social spaces in the contemporaneity, when operating with the concept of habitus.

KEYWORDS: Symbolic Borders. Ties of Belonging. Agent x Structure. Social Conditioning. Habitus. 


\section{CONDICIONANTES SOCIALES Y TRAJETORIAS SINGULAR: HABITUS COMO CLAVE ANALÍTICA EN PROCEDIMIENTOS DE CONSTITUCIÓN DE ENLACES DE PERTENENCIA Y FRONTERAS SIMBÓLICAS}

RESUMEN: El artículo parte de investigación de campo realizada en un barrio de la periferia de Santo André, Grande São Paulo, y discute los sentidos de pertenencia, o no, a la clase media, por parte de los moradores, frente a las políticas de inclusión social implementadas en la primera década de los años 2000, por los gobiernos estadual y federal. En un segundo momento enfatiza las fronteras simbólicas establecidas por un grupo de familias recién transferidas de área de favela a un condominio de edificios entregados como parte de la política de vivienda del Estado de Sao Paulo, cuestionando la preponderancia de las singularidades de las trayectorias individuales - que cruzan múltiples espacios sociales en los tiempos contemporáneos - cuando se opera con el concepto de habitus.

PALABRAS CLAVE: Fronteras simbólicas. Enlaces de pertenencia. Agente $x$ estructura. Condicionantes sociales. Habitus.

\section{Agradecimentos}

Registro meus agradecimentos à FAPESP que concedeu axílio para a realização desta pesquisa.

\section{REFERÊNCIAS}

BOURDIEU, Pierre. A distinção: crítica social do julgamento. São Paulo: EDUSP/ Porto Alegre: Zouk, 2007.

. What Makes a Social Class? On The Theoretical and Practical Existence Of Groups. Berkeley Journal of Sociology, Vol. 32, p.1-17, 1987.

. Gostos de classe e estilos de vida In: ORTIZ, Renato (org.) Bourdieu. Coleção Grandes Cientistas Sociais, São Paulo: Ática, 1983. p.82-121.

ELIAS, Norbert; SCOTSON, John L. Os estabelecidos e os outsiders. Rio de Janeiro: Zahar, 2000.

LAHIRE, Bernard. Indivíduo e Mistura de Gêneros: Dissonâncias Culturais e Distinção de Si. DADOS - Revista de Ciências Sociais, Rio de Janeiro, n. 4, vol. 50, no 4, p.795-825, 2007. 
Condicionantes sociais e trajetórias singulares: habitus como chave analítica em processos de constituição de elos de pertença e fronteiras simbólicas

ORTIZ, Renato (org.) Bourdieu. Coleção Grandes Cientistas Sociais, São Paulo, Ática, 1983.

PETERS, Gabriel. Habitus, reflexividade e neo-objetivismo na teoria da prática de Pierre Bourdieu. Revista Brasileira de Ciências Sociais. n.83,vol.28, p.47-71, 2013.

SETTON, Maria da Graça Jacintho. A escolha e o reconhecimento pela educação: o caso de Antonio. Revista Educação e Pesquisa, São Paulo, n. especial, v. 41, p.1405-1418, dez. 2015. Disponível em: <www.scielo.br/pdf/ep/v41nspe/1517-9702-ep-41-spe-1405.pdf.>. Acessado em: 18 mai. 2019.

. A teoria do habitus em Pierre Bourdeu: uma leitura contemporânea. Revista Brasileira de Educação. São Paulo, n.20, p.60-70, maio-ago de 2002. Disponível em: <www.producao.usp.br/.../handle/.../art_SETTON_A_socializacao_como_fato_social_t.... Acessado em: 18 mai. 2019.

Recebido em 13/02/2019.

Aprovado em 13/04/2019. 
